\title{
Extensiones de la Cuenta Satélite del Turismo: Matrices de gasto, viviendas turísticas y otros desarrollos recientes en el ámbito regional
}

\author{
Agustín Cañada Martínez \\ Dpto. Análisis Económico, Teoría e Historia Económica \\ Universidad Autónoma de Madrid
}

\section{RESUMEN}

El desarrollo de la Cuenta Satélite como instrumento de medición del Turismo y su relevancia económica, puede calificarse de espectacular: en 1999 tan solo siete países habían desarrollado esquemas de este tipo; en la actualidad, más de setenta países disponen de cuentas satélite del turismo (CST). Sin embargo, y a pesar del éxito internacional en su aplicación, se ha venido manifestando la necesidad de adaptar este instrumento contable a nuevas realidades dictadas por la evolución del turismo, y a nuevas necesidades de medición y análisis. En este trabajo se describen algunas de las principales extensiones de la cuenta, impulsadas por organismos internacionales, principalmente en la adaptación de la CST a ámbitos sub-nacionales o regionales: por un lado, las iniciativas vinculadas a la «Red de Conocimiento Regional» recientemente creada por la OMT, con énfasis especial en las matrices de consumo turístico regionales; un segundo aspecto es la redefinición de los agregados macro y los modelos de impacto del turismo a partir de la CST, tema de repercusión tanto a escala nacional como regional; y el tercer tema analizado se refiere a los retos metodológicos y estadísticos a escala nacional y regional, que plantea el tratamiento y medición de las segundas residencias turísticas en la CST.

Palabras clave: cuenta satélite del turismo, input-output, economía regional, OMT, SEC

Clasificación JEL: D57, E01, L83, O18 


\section{Presentación}

El desarrollo de la Cuenta Satélite como instrumento de medición de los aspectos económicos del Turismo y sus repercusiones económicas, puede calificarse de espectacular: en 1999 solo siete países habían desarrollado esquemas de este tipo; en la actualidad, más de setenta países disponen de CST, en algunos casos elaboradas periódicamente o incluso integradas en el sistema de cuentas nacionales (como en el caso de España). El éxito de estos esquemas se explica por una combinación de factores: el innegable auge del turismo como actividad económica; la propia aceptación de la cuenta como marco para la obtención de los agregados básicos del turismo; y, finalmente, la labor de apoyo y promoción de estos esquemas desarrollada por algunas instituciones internacionales (OMT, OCDE, Eurostat) y nacionales (como las impulsoras de la CST en España).

A pesar de este éxito en la aplicación de la CST, y como sucede siempre con estos instrumentos estadístico/ contables, deben ser continuamente puestos al día para adaptarse al carácter cambiante de la realidad económica que se trata de medir y para responder a nuevas demandas de los usuarios.

En este trabajo, que tiene un contenido y objetivos de tipo metodológico, se describen algunas de las principales extensiones de la cuenta satélite, actualmente en desarrollo por los organismos internacionales, vinculadas principalmente a la re-definición y adaptación de la CST a ámbitos sub-nacionales o regionales: en el apartado 2 se comentan las iniciativas vinculadas a la «Red de Conocimiento Regional» recientemente creada por la OMT, con énfasis especial en las matrices de gasto regionales; en el apartado 3, se describe un tema de repercusión tanto a escala nacional como regional, que es la definición de los agregados macro del turismo, los modelos de impacto y su vinculación con la cuenta satélite; en el apartado 4, los retos metodológicos y estadísticos que plantean para la CST y su dimensión regional el tratamiento y medición de las segundas residencias turísticas. El trabajo se completa con un apartado de reflexión final y dos anexos metodológicos que complementan las descripciones del texto principal. 


\section{LA MEDICIÓN DEL TURISMO Y SU RELEVANCIA ECONÓMICA} A ESCALA REGIONAL: EL PROGRAMA DE LA OMT

\subsection{La red de conocimiento regional INROUTE}

El interés por la extensión de la CST al ámbito regional, se ha venido manifestando desde hace años y se tradujo de hecho en la inclusión de un capítulo específico en la última versión de la metodología internacional, la y denominada TSA-RMF de 2008 (la versión precedente era del año 2000). (Véase OMT [2008])

Sin embargo, esa iniciativa ha resultado ser insuficiente y sobre todo en relación con la demanda creciente en todo el mundo acerca de esquemas y desarrollos en esta línea. Ya durante los últimos años, tanto la OMT como otras instituciones y países concretos, habían ido dando pasos en este ámbito. Mencionemos por ejemplo la conferencia de la CST regional OMT celebrada en Málaga en 2008 o la de la oficina de estadística inglesa de 2009 (Cañada (2009)).

Recientemente se ha iniciado uno de los proyectos más destacables en este campo de la CST regional, que es la recientemente creada Red internacional sobre economía regional, movilidad y turismo ( International Network on Regional Economics, Mobility and Tourism -INROUTE-) impulsada por la Organización Mundial del Turismo (OMT) y otras entidades internacionales y españolas ${ }^{1}$. La red «pretende convertirse en una referencia internacional para la reflexión y el intercambio de conocimiento sobre la medición y el análisis económico del turismo en el ámbito regional».

El núcleo fundamental de INROUTE es la creación de una red de expertos internacionales integrada por académicos, investigadores y profesionales, tanto de organismos públicos como privados para «compartir información, prácticas y experiencias que puedan promover el análisis comparativo, reforzar la base científica del turismo y proporcionar orientaciones en cuanto a la posición competitiva de destinos y proveedores de servicios turísticos».

Inicialmente se han identificado por los promotores de la Red cuatro áreas principales de investigación y análisis de aspectos regionales del turismo y la movilidad:

${ }^{1}$ La conferencia constitutiva de la red se celebró en Octubre de 2009 en San Sebastián («Primera Conferencia Internacional sobre la Medición y el Análisis Económico del Turismo Regional», 27 y 28 de octubre de 2009). 
1. Flujos de visitantes: flujos fronterizos e interregionales; utilización estadística de las fuentes administrativas; datos a partir del uso de nuevas tecnologías; herramientas de medida y análisis; modelos de previsión y otras herramientas contables.

2. Turismo y territorio: sistemas de indicadores (relacionados ambos con el territorio y la sostenibilidad); sistemas de información geográfica (GIS); relación entre las estadísticas del turismo y el medio ambiente.

3. Contribución económica del turismo: cuentas satélite del turismo (TSA); otras herramientas de modelización (tales como modelos de equilibrio general computacional, modelos econométricos e Input-output); empleo en las industrias de turismo.

4. Gestión de destinos turísticos: unidades estadísticas y de análisis; procedimientos de supervisión y evaluación; sistemas de indicadores.

Estos campos de actuación previstos en la red no son obviamente independientes entre sí; de hecho, el tema que se describe a continuación en este trabajo, que es la estimación de las matrices de gasto interregionales, se mueve a caballo entre varios de esos campos, ya que como a continuación se verá, lo que es inicialmente un método para la cumplimentación de CST en el ámbito regional, se convierte también en instrumento auxiliar para la determinación de los PIB y los modelos de impacto del turismo.

\subsection{Las matrices interregionales: flujos turísticos y flujos de consumo.}

Para comprender el alcance del proyecto de las matrices regionales de consumo, es necesario situar esta metodología en un marco más amplio de estimación que es el de la CST a escala regional. Sin entrar en detalles excesivos, podemos recordar que el tema de la dimensión regional de la CST se mueve entre las dos grandes alternativas conceptuales y metodológicas - que son las mismas a las que se enfrenta la elaboración de la contabilidad regional - y que esquemáticamente podríamos indicar como «regionalización» vs. «estimación regional»: en el primer caso, se trata de regionalizar o distribuir territorialmente la CST de un país mediante distintos indicadores; en el segundo, de calcular de manera independiente la CST para un área o región concreta, vinculándola por ejemplo, a las tablas I-O y cuentas regionales de esa región (Cañada (2009)). 
Sin embargo, y es una de las propuestas básicas que se intenta desarrollar en la Red de la OMT, existe una vía «intermedia» en la que, al menos en determinados aspectos, se trata de buscar una compatibilidad entre los dos planteamientos: se podría estudiar la posibilidad de que las estimaciones de la Cuenta Satélite del país se desarrollaran de forma paralela a las estimaciones desagregadas de las regiones o áreas que lo componen. La ventaja es aprovechar los recursos utilizados y garantizar que los dos tipos de estimaciones fueran compatibles.

Evidentemente, este planteamiento requiere - aparte de otros temas que escapan al alcance de este trabajo: el establecimiento de acuerdos entre las instituciones de los diferentes ámbitos territoriales (administraciones centrales y regionales) - el desarrollar instrumentos específicos de tipo conceptual y estadístico, que garanticen esa compatibilidad. Uno de ellos sería la elaboración conjunta, por las distintas instituciones implicadas, del instrumento que aquí se propone y que contribuiría a la mejora de todo el sistema estadístico sobre el turismo: las matrices de origen/ destino del gasto turístico por regiones.

Como punto de partida y para precisar el alcance de estas matrices, se ha construido el esquema 1 que recoge, por filas, los flujos de viajes turísticos por regiones de residencia u origen del viajero, y por columnas, por región de destino del viaje. Hay que resaltar que esta es una matriz de flujos no monetarios (pueden ser viajes, viajeros $\mathrm{u}$ otras variables indicativas).

Las casillas de la diagonal principal representarían los flujos intra regionales, (lo que se denomina el «turismo interno» en una zona) y el resto los flujos interregionales. Los viajeros que llegan a una región desde otras constituyen el «turismo receptor»; para la región de origen de los viajes, son «turismo emisor». Por ejemplo $F_{12}$, que representa el $n^{\circ}$ de viajeros con residencia en la región 1 y destino del viaje en la región 2, sería simultáneamente, un flujo receptor para la región 2 y un flujo emisor para la región 1. 
EsQuema 1.—Matriz de flujos (viajes/ viajeros) regionales de «turismo»

\begin{tabular}{|c|c|c|c|c|c|c|}
\hline & \multicolumn{5}{|c|}{ Área de destino de los flujos } & \multirow[b]{2}{*}{$\begin{array}{l}\text { Total } \\
\text { flujos por } \\
\text { región de } \\
\text { origen }\end{array}$} \\
\hline $\begin{array}{l}\text { Área de origen } \\
\text { de los flujos }\end{array}$ & Región 1 & Región 2 & $\ldots \ldots$ & Región n & $\begin{array}{l}\text { Resto del } \\
\text { Mundo }\end{array}$ & \\
\hline Región 1 & $\mathrm{~F}_{11}$ & $\mathrm{~F}_{12}$ & $\ldots \ldots$ & $\mathrm{F}_{1 \mathrm{n}}$ & $\mathrm{F}_{1 \mathrm{E}}$ & $\mathrm{F}_{1_{*}}$ \\
\hline Región 2 & $\mathrm{~F}_{12}$ & $\mathrm{~F}_{22}$ & $\ldots \ldots$ & $\mathrm{F}_{2 \mathrm{n}}$ & $\mathrm{F}_{2 \mathrm{E}}$ & $\mathrm{F}_{2_{*}}$ \\
\hline$\ldots \ldots$ & ....... & ...... & $\ldots \ldots$ & ....... & ....... & ...... \\
\hline Región n & $\mathrm{F}_{\mathrm{n} 1}$ & $\mathrm{~F}_{\mathrm{n} 2}$ & $\ldots \ldots$ & $\mathrm{F}_{\mathrm{nn}}$ & $\mathrm{F}_{\mathrm{nE}}$ & $\mathrm{F}_{\mathrm{n}_{*}}$ \\
\hline Resto del mundo & $\mathrm{F}_{\mathrm{R} 1}$ & $\mathrm{~F}_{\mathrm{R} 2}$ & $\ldots \ldots$ & $\mathrm{F}_{\mathrm{Rn}}$ & & \\
\hline $\begin{array}{l}\text { Total flujos por } \\
\text { región de destino }\end{array}$ & $\mathrm{F}_{* 1}$ & $\mathrm{~F}_{* 2}$ & $\ldots \ldots$ & $\mathrm{F}_{*} \mathrm{n}$ & & \\
\hline
\end{tabular}

Se añaden además dos elementos para tener en cuenta los flujos con el resto del mundo: Una fila para los viajes de no residentes al territorio del país; y una columna para los viajes de residentes del país al exterior (Resto del Mundo). Es decir, es la desagregación regional de los flujos receptores y emisores del país en su conjunto.

Ahora se trata de pasar de ese concepto de flujos físicos a variables monetarias y para eso, se va a utilizar el «consumo turístico», la variable principal de demanda de una CST ${ }^{2}$

${ }^{2}$ En el anexo 1 de este trabajo se han resumido los rasgos principales de la variable «consumo turístico» en una CST. Sobre el tema, todavía sin consenso a nivel internacional, de la formación bruta de capital fijo en una CST, la descripción más completa sigue siendo la de Holz-Eakin (2001). 
—véase anexo 1- cuya matriz regional se representa en el esquema 2. Esta es una matriz estrechamente vinculada a la de los flujos del esquema 1, con un formato equivalente pero como a continuación se indica, con notables matizaciones y diferencias. Precisamente uno de los objetivos de este programa de Inroute debe ser la clarificación metodológica y estadística sobre las vinculaciones y diferencias entre unos y otros parámetros (monetarios y no monetarios).

EsQuema 2.-Matriz de flujos regionales de «consumo turístico»

\begin{tabular}{|c|c|c|c|c|c|c|}
\hline & \multicolumn{5}{|c|}{ Región/ territorio al que se asigna el consumo } & \multirow{2}{*}{$\begin{array}{c}\text { Total } \\
\text { consumo } \\
\text { por área } \\
\text { de origen }\end{array}$} \\
\hline $\begin{array}{l}\text { Área de origen } \\
\text { de los flujos } \\
\text { (viajes/ viajeros) }\end{array}$ & Región 1 & Región 2 & ...... & Región $n$ & $\begin{array}{l}\text { Resto del } \\
\text { mundo }\end{array}$ & \\
\hline Región 1 & $\mathrm{C}_{11}$ & $\mathrm{C}_{12}$ & $\ldots \ldots$ & $\mathrm{C}_{1 \mathrm{n}}$ & $\mathrm{CTE}_{1}$ & $\mathrm{C}_{1_{*}}$ \\
\hline Región 2 & $\mathrm{C}_{21}$ & $\mathrm{C}_{22}$ & ...... & $\mathrm{C}_{2 \mathrm{n}}$ & $\mathrm{CTE}_{2}$ & $\mathrm{C}_{2_{*}}$ \\
\hline ...... & ...... & ....... & ....... & ....... & ....... & $\ldots \ldots$ \\
\hline Región n & $\mathrm{C}_{\mathrm{n} 1}$ & $\mathrm{C}_{\mathrm{n} 2}$ & ...... & $\mathrm{C}_{\mathrm{nn}}$ & $\mathrm{CTE}_{\mathrm{n}}$ & $\mathrm{C}_{\mathrm{n}_{*}}$ \\
\hline Resto del mundo & $\mathrm{CTR}_{1}$ & $\mathrm{CTR}_{2}$ & ...... & $\mathrm{CTR}_{\mathrm{n}}$ & & CTR \\
\hline $\begin{array}{l}\text { Total consumo por } \\
\text { área de destino }\end{array}$ & $\mathrm{C}_{* 1}$ & $\mathrm{C}_{* 2}$ & ...... & $\mathrm{C}_{* \mathrm{n}}$ & CTE & \\
\hline
\end{tabular}

En la sub-matriz definida por las $\mathrm{n}$ regiones, las casillas de la diagonal principal corresponden al consumo de viajes de los residentes dentro del territorio de su región; es decir, sería lo que se denomina en la CST el «consumo turístico interno» pero para cada región. Aunque como indica el término, el concepto tiene que ver obviamente con los gastos ligados al turismo interno, aquí se incluyen — véase anexo 1 - los gastos vinculados a viajes a otras regiones, pero que se materializan en una 
compra de servicios en la propia región (por ejemplo, a una agencia de viajes de la región antes de salir de viaje ${ }^{3}$ ).

Las casillas fuera de la diagonal principal, se refieren a los gastos de viajes ligados al turismo receptor / turismo emisor, según la perspectiva adoptada. Pero de nuevo aquí hay que señalar que se está hablando de gastos ligados a la realización de viajes y por tanto se tienen que hacer varias matizaciones: por ejemplo $\mathrm{C}_{12}$, recogería los gastos vinculados a los viajes de residentes en la región 1 que visitan la región 2 . Si se analiza desde el punto de vista de la región «receptora», la 2, en esos gastos no se incluirían los que el viajero haya hecho previamente en su región de origen (que, como se ha indicado se incluyen en el C. T. interno). Pero en sentido contrario, no se restringen solo a los gastos que el viajero realiza en esa región de destino de su viaje, sino que incluirían por ejemplo si el viajero ha utilizado una compañía de transporte residente en la región de destino. En términos más precisos de la contabilidad —véase anexo 1- se incluiría tanto el consumo de no residentes como otras exportaciones vinculadas al viaje.

Además en estas matrices se consigue una simetría y compatibilidad en las mediciones de las distintas regiones: $\mathrm{C}_{12}$ desde la perspectiva de la región 2 seria parte de su «consumo turístico receptor»; y desde la perspectiva de 1, parte de su «consumo turístico emisor».

Se han añadido una fila y una columna que representan, respectivamente, lo que era el consumo turístico receptor y el consumo turístico emisor para el conjunto de la nación, distribuido por regiones. Así, $\mathrm{CTR}_{1}$ representa el consumo turístico receptor del país, pero en la parte correspondiente a la región 1; $\mathrm{CTE}_{1}$ el consumo turístico emisor del país en la parte correspondiente a los viajes de los residentes en la región 1 al extranjero.

${ }^{3}$ Aunque se ha tomado como ejemplo ilustrativo de la localización de los gastos de un viaje, el sector de agencias de viaje y los servicios que prestan, son actividades que están experimentando una transformación muy profunda ligadas al desarrollo de Internet y las nuevas tecnologías, tanto desde la perspectiva de los productores — con el desarrollo de las agencias mayoristas y minoristas en la Web- como de los consumidores con el incremento de posibilidades de autoorganización de los viajes. Además de la progresiva desaparición del sector minorista (de locales al público) existen importantes problemas para la asignación de los gastos de estos intermediarios a unas y otras áreas, dado el carácter plurinacional y el sistema de crecientes interrelaciones entre empresas. Esto se une a (e incrementa aún más) el problema tradicional, verdadero reto de la CST, del tratamiento de los «paquetes turísticos». Véase por ejemplo OMT(2008) o INE(2009) 
Por ejemplo, el «consumo turístico interior» en la región 1 sería el total de la columna correspondiente:

$$
\left.\mathrm{C}_{* 1}=\mathrm{C}_{11}+\underset{\mathrm{h}}{\left(\sum \mathrm{C}_{\mathrm{h} 1}\right.}+\mathrm{CTE}_{1}\right)
$$

Donde $\mathrm{C}_{11}$ es el consumo turístico interno de la región, $\mathrm{C}_{\mathrm{h} 1}$ es el consumo por viajes de una región h a la región 1 . El hecho de tratar cada región como una entidad perfectamente definida desde el punto de vista económico, implica que todas las transacciones con otras regiones deben registrarse como transacciones con el resto del mundo, de manera similar a los de la economía nacional con otros países.

Por esa razón, como se indica con el paréntesis en la ecuación, el consumo turístico receptor tiene a escala regional, dos componentes: los gastos ligados a viajes desde otras regiones $\left(\sum \mathrm{C}_{\mathrm{h} 1}\right)$ y los gastos por viajes desde el resto del mundo $\left(\mathrm{CTE}_{1}\right)$.

De la anterior presentación se derivan algunas consecuencias de interés, no sólo para la elaboración de CST regionales, sino incluso para algo más general y previo que es la estimación del «Sector Resto del Mundo» en las Contabilidades y tablas I-O regionales. Porque como es sabido, salvo pequeñas diferencias —véase anexo 1-, estimar la matriz anterior supone estimar los conceptos de «consumo de no residentes en el territorio (regional)» y del «consumo de residentes (de la región) en el resto del mundo» así como otros componentes de exportaciones e importaciones vinculadas a los viajes turísticos.

\subsection{Aspectos prácticos de la estimación de las matrices}

Una de las implicaciones de los esquemas anteriores desde el punto de vista de la elaboración práctica de las matrices es que resulta conveniente tratar de diferenciar, en las estadísticas y en los métodos de cálculo, entre los gastos que se realizan en el lugar de «origen» del viaje (por ejemplo, antes de la salida). Con esa finalidad pude ser útil plantear una clasificación como la del cuadro 1 adjunto, en el que los gastos más representativos de un viaje (realizado por un residente en la región 1 que se desplaza a la región 2) se han diferenciado por productos, según que el lugar preferente o habitual de adquisición de los productos. 
CuAdro 1.-Gastos ligados a un visitante que reside en la región 1 y viaja a la región 2: lugar donde preferentemente se realiza el Gasto en consumo

\begin{tabular}{|c|c|}
\hline $\begin{array}{l}\text { Gasto en consumo vinculado al territorio de } \\
\text { origen del viaje (región 1) }\end{array}$ & $\begin{array}{l}\text { Gasto en consumo vinculado al territorio de } \\
\text { destino del viaje (región 2) }\end{array}$ \\
\hline $\begin{array}{l}\text { - Transporte larga distancia } \\
\text { - Servicios de agencias de viajes (en origen) } \\
\text { - Bienes y servicios adquiridos previa y } \\
\text { posteriormente a la realización de un viaje } \\
\text { (vestido, material fotográfico, gasolina, } \\
\text { seguros...) } \\
\text { - Alquiler de vehículos }(*)\end{array}$ & $\begin{array}{l}\text { - Alojamiento } \\
\text { - S. Restauración } \\
\text { - Transporte urbano o corta distancia } \\
\text { - Servicios de agencias de viajes (en destino) } \\
\text { - Alquiler de vehículos }(*) \\
\text { - S. Recreativos / Culturales / Deportivos } \\
\text { - Otros bienes (artesanía, souvenir, } \\
\text { diversos...) y servicios consumidos durante } \\
\text { el viaje en el área de destino. } \\
\text { - «Márgenes» de Comercio. } \\
\text { - Otros servicios. }\end{array}$ \\
\hline
\end{tabular}

(*) Algunas categorías se reparten entre los dos posibles territorios de adquisición

En la columna izquierda, se localizan los productos cuyo gasto se realiza en muchos casos en la región de origen, como por ejemplo, la utilización de servicios de agencias de viaje en la propia zona donde se reside, o la utilización de una compañía de transporte de la zona de origen; en la derecha, los gastos que por lo general se realizan en la región de destino o, siendo aquí más taxativo, que se refieren a productos que por definición no se pueden consumir mas que en el lugar de su suministro (producción): alojamiento, servicios de restaurantes y bares, transporte urbano en el lugar visitado, servicios culturales o recreativos...

Esta diferenciación, aunque como se indica en el cuadro 1, tiene un carácter aproximado, es interesante por ejemplo de cara a la construcción en la práctica de las mencionadas matrices, y en general como orientación de trabajos prácticos de estimación regional de la CST.

Una segunda observación, útil para la estimación de la matriz de gasto, sería la que inspira el cuadro 2 en el que se establece una clasificación de los productos según lo que se ha denominado «opciones de estimación». Porque cabe señalar que existe la posibilidad de estimar la demanda (gasto) de determinados productos a partir de datos de oferta regionales (también es aplicable para el conjunto de la nación). Obviamente esto es posible en los productos característicos del turismo con una elevada ratio de especialización turística, es decir, cuando existe casi una identidad entre la oferta y la demanda o utilización por los turistas. Es decir, que ya sea bajo una perspectiva de que se consuman en origen, ya se que se consuman en destino, su producción estará orientada al turismo. 
CuADro 2.-Clasificación de los productos según el tipo de procedimiento de estimación del consumo turístico

\begin{tabular}{|l|l|}
\hline Categoría de productos & Procedimiento para estimar la demanda \\
\hline $\begin{array}{l}\text { Transporte larga distancia (segmentos } \\
\text { específicos) }\end{array}$ & Oferta \\
\hline Agencias de viaje & Oferta \\
\hline Alojamiento colectivo & Oferta \\
\hline Alquiler de vehículos & Oferta \\
\hline S Restauración & Oferta/ demanda \\
\hline Transporte urbano o corta distancia & Demanda \\
\hline Alojamiento privado: alquiler real & Demanda \\
\hline Alojamiento privado: vivienda en propiedad & Oferta/ demanda $(*)$ \\
\hline Otros (artesanía, souvenir...) & Demanda \\
\hline Márgenes de Comercio & Oferta/ demanda $(*)$ \\
\hline S. Recreativos / Culturales / Deportivos & Oferta/ demanda \\
\hline
\end{tabular}

(*) Procedimientos específicos

Los ejemplos son los obvios: agencias de viajes; algunos medios y segmentos específicos del transporte de pasajeros (por ejemplo, el aéreo, el ferrocarril de larga distancia...); los hoteles y otros alojamientos colectivos; y, en menor medida, el alquiler de coches. Aunque la oferta de estos productos pudiera no estar orientada al turista al $100 \%$, las ratios turísticas son lo bastante elevadas como para permitir esa estimación regional de la demanda (del gasto) usando datos de oferta.

Dicho de otra forma, para cada uno de esos productos sería posible conocer el total de la columna de la matriz de gasto anteriormente expuesta, simplemente a partir de estimaciones de la oferta (por ejemplo, información sobre el volumen de ventas por establecimientos en las distintas regiones). Naturalmente, son necesarias estimaciones adicionales para completar las distintas casillas de la matriz. Pero aquí se podría ya acudir a fuentes no monetarias o a combinaciones de fuentes monetarias y no monetarias ${ }^{4}$.

${ }^{4}$ Por ejemplo, tomando España como referencia para los hoteles, las encuestas sobre ocupación de alojamientos colectivos del INE, proporcionan el número de pernoctaciones por región de origen y región de destino para los residentes. Por lo tanto, con estos datos se puede elaborar una matriz de flujos físicos interregionales. Además, se puede transformar esta matriz en una matriz monetaria con la información proporcionada por encuestas económicas del INE sobre este sector (índices de precios e ingresos hoteleros). Ejemplos prácticos exhaustivos de este tipo se pueden 
Obviamente, en otros productos son necesarios datos de demanda (regional): bares y restaurantes; servicios recreativos, deportivos y culturales; bienes; medios específicos de transporte... Este conjunto de productos solamente se puede estimar a partir de fuentes específicas de gasto, dado que su demanda no está orientada exclusiva ni principalmente al turista, sino que abarca a todos los consumidores.

Finalmente, existen algunos otros productos muy específicos que solamente pueden ser estimados mediante una combinación de oferta y demanda, pues no caben exacta o únicamente en una sola de las aproximaciones indicadas. Éste es el caso por ejemplo del alojamiento privado, (que se trata en el apartado 4).

Del análisis anterior surgen varias recomendaciones básicas para la estimación de estas matrices: por un lado, que aunque la elaboración de matrices de flujos es un paso conveniente y casi necesario para la construcción de matrices monetarias, no deben confundirse ambos planteamientos, porque como se ha visto, no existe una identidad entre las celdas correlativas de las dos matrices; de otro lado, que los datos de gasto turístico - y las matrices regionales - deben estar desagregados al menos en algunas categorías esenciales de productos (el ideal es acercarse a los «productos característicos» más relevantes), porque esto facilitará las tareas de estimación (por ejemplo, el estimar el total de demanda a través de la oferta) y también la diferenciación en las hipótesis y cálculos sobre gasto en origen y en destino; precisamente en relación con este aspecto, una recomendación evidente de tipo estadístico es el tratar de que en las encuestas a los turistas se diferencie entre esos gastos en origen y en destino ${ }^{5}$.

Por último, aunque esta propuesta se enfrenta a los problemas de carencias estadísticas, ya que se hablaba de la conveniencia de diferenciar el gasto por productos, también sería deseable - porque en cierta medida ayuda a complementar esa desagregación por productos - que hubiera un cierto desglose de las matrices según segmentos o tipología de viajeros.

$\mathrm{Al}$ menos dos dimensiones deberían ser consideradas: ${ }^{6}$ motivo principal del viaje, aunque sería suficiente con poder identificar la categoría de «viajes de negocios»; y otra categoría, con rasgos muy singulares, que es la de los viajes/ viajeros que utilizan

ver en diferentes trabajos de Carlos Llano y Tamara de la Mata realizados en el marco del proyecto «C-Intereg» de estimación de las balanzas regionales en España.

5 Por ejemplo, la «Encuesta de gasto turístico» española, elaborada por el Instituto de Estudios Turísticos (Ministerio de Industria) incluye esa diferenciación.

${ }^{6}$ Para simplificar el texto, se omiten muchas otras diferenciaciones importantes a la hora de elaborar las matrices. Por ejemplo la conveniencia de diferenciar - problemas estadísticos aparte - 
como alojamiento una vivienda privada, especialmente si la vivienda es propiedad del usuario. A la justificación de estos desgloses se dedican los siguientes apartados.

\section{LOS AGREGADOS MACRO Y LOS MODELOS DE IMPACTO ECONÓMICO A PARTIR DE LA CST: ALGUNAS PROPUESTAS DE REDEFINICIÓN A ESCALA NACIONAL Y REGIONAL}

\subsection{Sobre la CST como instrumento contable: el PIB turístico}

Entre las aportaciones innegables de la CST y sus promotores está el haber diseñado un procedimiento para la medición de todas las variables fundamentales del turismo y para la definición de la industria turística, bajo un prisma más completo y exacto de lo que eran los métodos convencionales previos a la CST. Y ha conseguido además que esos procedimientos se aceptaran como estándar a nivel internacional.

No obstante, un aspecto cuestionable de la CST, donde se ha venido dando mayor desacuerdo entre los distintos estudiosos e instituciones implicadas, prácticamente desde la aprobación de la primera versión de la TSA-RMF (en el año 2000) es en la definición de los indicadores agregados de relevancia del turismo, como el PIB turístico.

Para comprender el origen del problema y presentar las soluciones sugeridas, se van a utilizar esquemas muy simples basados en las Tablas de Origen y Destino (TOD) de la contabilidad nacional y, alguna ecuación de referencia. Sin embargo, para facilitar la exposición de los distintos puntos, los aspectos analíticos más detallados, se han incluido en el anexo 2.

El punto de partida de la estimación de la CST es la Tabla de destino, dado que ésta recoge los aspectos de demanda, que constituyen la esencia del turismo: el turismo surge por el hecho de que los agentes económicos realizan unos viajes - delimitados de acuerdo con determinados convenios - OMT (2008) - y eso implica una demanda en productos ligados a esos viajes. Por tanto, la demanda total es la suma de las demandas de cada uno de los productos.

La segunda fase consiste en definir la oferta: Utilizando la tabla de origen (adaptada a la CST y descontando las importaciones) si la demanda turística de un producto es abastecida por diferentes sectores productivos (ramas en la terminología contable)

los flujos y el gasto de excursionistas por un lado, y de los turistas (es decir, viajeros que pernoctan en el lugar visitado) por otro. 
entonces se trata de identificar todas las ramas implicadas en la oferta de productos al turismo, y de calcular la parte orientada al turismo en la producción de cada una de ellas.

Posteriormente, en una fase 3 , una vez que se ha obtenido, por ramas o sectores de actividad, la producción que satisface la demanda de bienes y servicios, entonces sería posible obtener el VAB por ramas, a partir de un cálculo de los consumos intermedios respectivos (que pueden basarse en estadísticas o en cálculos indirectos)

En términos analíticos muy básicos, para una rama j el valor añadido generado por el turismo, $\mathrm{VTj}$, sería

$$
\mathrm{VTj}=\mathrm{ZTj}-\mathrm{XTj}
$$

Siendo ZTj la producción destinada al turismo y XTj los consumos intermedios correspondientes a dicha producción.

La suma de los valores añadidos para todas las ramas que intervengan en el suministro de productos a los turistas, junto con los Impuestos netos de subvenciones (con la notación $\boldsymbol{\tau}$ ) vinculados a la demanda turística (definida para los i productos) permite llegar al cálculo del PIB turístico:

$$
\operatorname{PIBT}=\underset{j}{\Sigma} \underset{\mathrm{i}}{\Sigma} \mathrm{i}
$$

Esta fórmula de la TSA-RMF se utiliza para calcular el PIB directamente relacionado con la demanda turística, pero de forma que, como se ha visto, compatibiliza la demanda con una aproximación de oferta, a través de estas variables de las ramas productoras de bienes y servicios al turismo.

\subsection{Una medida global del impacto económico del turismo}

La anterior definición del PIB turístico adoptada por la TSA-RMF es limitada cuando se trata de analizar el peso económico del turismo de una forma más global. La razón reside en que la demanda turística incluye gastos correspondientes a la variable «consumos intermedios», que serían los ligados a los mencionados «viajes de negocios». Aunque evidentemente estos gastos forman parte del consumo turístico total, la lógica contable revela que cuando se realiza una medición o evaluación global del turismo, los consumos intermedios no se incluyen en el valor global del PIB de una economía, ya 
que corresponden simultáneamente a ingresos corrientes (por venta de producción) de unas ramas de actividad y a gastos corrientes (consumos intermedios) de otras ramas, siendo nulo el saldo global de estos intercambios para el total de la economía.

Pero además este tipo de limitaciones de la CST está además muy estrechamente vinculada con los modelos de impacto económico del turismo. Sin entrar en detalle en un tema sobre el que por otra parte existe una extensa literatura ${ }^{7}$, los modelos de impacto económico basados en la CST se ven también lastrados por esa ilimitación e indefinición sobre los aspectos de demanda.

A los efectos de lo que aquí se quiere comentar, nos basta con tomar como referencia un planteamiento convencional «tipo Leontief», o lo que simplificando podríamos denominar una perspectiva «input-output»: las ramas directamente abastecedoras de turismo demandan de forma indirecta otros bienes y servicios (la demanda intermedia) que a su vez generarán sucesivos impactos en el sistema...

Por ejemplo, un modelo convencional I-O, basado en las TOD - que se define en el anexo 2 - sería:

$$
\mathrm{Z}=\mathrm{U}^{-1}\left(\mathrm{I}-\mathrm{W} \mathrm{U} \mathrm{U}^{-1}\right)^{-1}(\mathrm{Y}-\mathrm{M})
$$

Donde las variables son matrices o vectores obtenidos de las TOD: $Z$ es el vector de producción por productos o ramas homogéneas; Y, el vector de demanda final por productos; $\mathrm{M}$ el vector de importaciones por productos; y el resto son coeficientes obtenidos de las TOD - véase anexo 2 - que determinan los multiplicadores de impacto de la demanda.

Ese tipo de modelos no son aplicables directamente a la obtención del impacto producido por la demanda turística DT en una zona, puesto que:

$$
\mathrm{DT}=\mathrm{X}^{\prime} \mathrm{T}+\mathrm{YT}
$$

Siendo X'T la demanda turística intermedia e YT la demanda turística final (todos los términos como un vector de totales por productos). Por tanto, no se puede utilizar un modelo convencional, porque los gastos de los viajes de negocios estarían simultá-

${ }^{7}$ El lector interesado puede encontrar referencias bastante completas y actualizadas en BONN (2008). 
neamente como variable endógena, (incluidos en la matriz A) y como variable exógena (en el vector de demanda).

\subsection{Procedimientos alternativos: demanda final y demanda final «ampliada»}

Una de las alternativas propuestas, la más elemental y casi obvia, consistiría en calcular el PIB turístico (o los modelos de impacto) exclusivamente a partir de la demanda turística final, ya que cualquier gasto en un componente de la demanda final se traslada íntegramente al PIB (suponiendo que están adecuadamente contemplados los temas de valoración y de contenido en importaciones de la demanda turística). Es un procedimiento tan simple que de hecho implica que el cálculo de la aportación del turismo al PIB se podría realizar como un paso casi inicial en la elaboración de una CST (en la medida en que el elemento básico para estimar la cuenta son los datos de demanda).

Además en este caso, se pueden obtener matrices de multiplicadores de la producción directa e indirecta ligada a la demanda final turística a partir de la ecuación anterior:

$$
\mathrm{ZT}=\mathrm{U}^{-1}\left(\mathrm{I}-\mathrm{W} \mathrm{U} \mathrm{U}^{-1}\right)^{-1}(\mathrm{YT}-\mathrm{M})
$$

Donde ZT (producción multiplicativa del turismo) es un vector de la producción turística de todas las ramas de la economía que es generada directa e indirectamente por el turismo.

El segundo procedimiento propuesto para obtener medidas globales y/o esquemas de impacto consistiría en «exogeneizar» esos gastos de viajes de negocios, extrayéndolos de la matriz de consumos intermedios y llevándolos como un vector adicional a la demanda final, que quedaría ahora como una demanda final ampliada a efectos de la CST.

En términos de la demanda final turística - véase anexo 2 - el nuevo modelo quedaría:

$$
\mathrm{ZT}=\mathrm{U}^{*-1}\left(\mathrm{I}-\mathrm{W}^{*} \mathrm{U}^{*-1}\right)^{-1}\left(\mathrm{YT}^{*}-\mathrm{M}\right)=\mathrm{U}^{*-1}\left(\mathrm{I}-\mathrm{W}^{*} \mathrm{U}^{*-1}\right)^{-1}(\mathrm{DT}-\mathrm{M})
$$

Donde el asterisco indica que se está utilizando unas TOD modificadas con esa «exogeneización» de la demanda intermedia por viajes de negocios. Como se ve en la ecuación, YT* coincide ahora con la demanda turística total DT. 
La limitación evidente de este método es que, supone modificar de hecho la imagen que se proporciona de una economía a través de las TOD y las cuentas nacionales. Por ejemplo, y como es obvio, al hacer esta modificación habría que considerar también, a los efectos de la CST, un PIB alternativo a (y mayor que) el de las cuentas nacionales.

No obstante, y en defensa de esta solución, se pueden mencionar dos aspectos -véase anexo 2-: en primer lugar, que el efecto sobre el PIB se ve mitigado por el hecho de que equivaldría sólo a la parte de los viajes de negocios de las actividades de mercado, ya que por los convenios de las cuentas nacionales, la reclasificación de los de las ramas de no mercado es nulo en términos del PIB; en segundo lugar, otra ventaja de esta alternativa es que al quedar toda la demanda turística como exógena se facilitaría el cálculo de la «aportación del turismo al $\mathrm{PIB}$ » y de los efectos directos e indirectos de productos específicos del turismo sobre el resto de las actividades ${ }^{8}$.

\subsection{La redefinición del PIB y el turismo de negocios en el ámbito regional}

Se vuelve de nuevo en este apartado al ámbito regional. Evidentemente, los principios fijados en los anteriores esquemas son aplicables también a escala regional. Sin embargo, existen diferencias conceptuales y también cuantitativas dignas de mencionarse, que nos sirve para enlazar con las iniciativas específicas de matrices, en el campo regional, que se mencionaban en el apartado anterior.

Cuando se desciende a una perspectiva regional dentro de un país, el papel y significado de los gastos de viajes de empresas cambian sustancialmente: como se señalaba en el epígrafe 2, los «no-residentes» que visitan una región incluirían (junto con los viajeros extranjeros o internacionales) los viajeros de negocios procedentes de otras regiones. Es decir, que desde la perspectiva regional, una buena parte de los flujos que antes eran endógenos (consumos intermedios a nivel nacional) ahora pasan a exogeneizarse.

Por tanto, el ajuste a realizar en el PIB turístico de una región (o en modelos de impacto) por el tema de los consumos intermedios internos puede tener una dimensión cuantitativa menor que escala nacional: Es el caso de regiones con reducida dimensión territorial y/o económica, en las que los flujos internos (intrarregionales) por viajes de negocios pueden ser de escasa entidad; y como contrapartida serán mucho mayo-

8 Tema que tiene un alcance mayor aún que el del análisis del turismo. Véase anexo 2. 
res comparativamente los flujos interregionales receptores o emisores de este tipo de viajes.

Es decir, que esta argumentación refuerza la necesidad de que se elaboren matrices interregionales pero además ahora diferenciadas por motivo de viajes (al menos gasto de viajes de negocios y el resto) única forma de realizar estimaciones consistentes de la aportación del turismo al PIB.

\section{Problemas Metodológicos en el tratamiento de las SEGUNDAS RESIDENCIAS TURÍSTICAS EN LA CST: IMPLICACIONES REGIONALES}

Puede decirse que el tema de las viviendas o el alojamiento privado para uso turístico, que se aborda en este apartado, constituye todavía hoy, trascurridos más de diez años desde la publicación de la metodología internacional de la CST, una de las asignaturas pendientes para los contables y los estadísticos, en las que no se ha llegado a encontrar ni métodos ni propuestas estadísticas adecuados para resolver los importantes problemas de medición que plantea este tipos de «productos».

Pero además, es un tema que tiene una dimensión incluso más amplia que la de la CST, porque afecta a las mediciones de contabilidad nacional y balanza de pagos de los países.

De hecho, el tema ha resurgido en proyectos recientes vinculados inicialmente a las cuentas nacionales y la balanza de pagos: En la actualidad, y a iniciativa de la Comisión para Europa de las Naciones Unidas, con la colaboración de distintos organismos internacionales, se está elaborando un manual sobre los problemas y retos que plantea la globalización para las cuentas nacionales. La participación de la OMT en la redacción del capítulo sobre viviendas turísticas ha ayudado a impulsar y revitalizar el interés por el tema en el ámbito de la propia $\mathrm{CST}^{9}$.

9 El autor de este artículo ha colaborado con la OMT en la elaboración de un documento (Libreros y Cañada (2010)) sobre viviendas turísticas en la CST, que se utiliza para la redacción del capítulo 10 de la futura publicación de las Naciones Unidas («Impact of Globalisation on National Accounts: Practical Guidance». Se tiene previsto finalizar la publicación durante el año 2010, tras la reunión del «Grupo de expertos de cuentas nacionales» a celebrar en Ginebra el mes de Abril). 


\subsection{Problemas generales en el tratamiento y medición de las viviendas de uso turístico en las cuentas nacionales y en la CST}

Antes de describir su singularidad, conviene aclarar que la utilización de viviendas para uso turístico, engloba dos casos muy diferentes desde la perspectiva de cuentas nacionales y la CST: cuando el turista utiliza una vivienda ajena por la que paga un alquiler; y cuando el turista utiliza una vivienda de su propiedad. El primer caso plantea solo problemas estadísticos; eso sí, muy importantes, porque la mayor parte de la oferta de este tipo de alojamientos se mueve dentro de la economía informal o irregular, correspondiendo a transacciones entre particulares, que en su gran mayoría escapan a las fuentes estadísticas ${ }^{10}$.

Pero donde verdaderamente reside el problema es con los apartamentos y casas de vacaciones utilizados por sus propietarios, ya que aquí a las limitaciones estadísticas se unen o se superponen de manera predominante los aspectos metodológicos

Para entender la raíz del tema, hay que aclarar que surge por un criterio tradicional de la contabilidad nacional, en virtud del cual se considera, como si de otra actividad productiva se tratara, que las viviendas prestan a los propietarios que las ocupan unos servicios de alojamiento. Para realizar esta imputación, los hogares propietarios de las viviendas en las que habitan se consideran como empresas («cuasi-sociedades») que producen unos servicios de vivienda. Servicios que son consumidos por el propio hogar que los produce $y$, por tanto, incluidos en el gasto en consumo final de los hogares. Las rentas que se obtienen por esa «auto-venta» (una vez que se descuentan los costes de producción) se consideran una renta primaria del hogar (un «excedente bruto de explotación») con la que se paga precisamente el consumo, la «adquisición» de esos servicios.

Conviene señalar que este criterio de imputación se aplica para cualquier tipo de alojamiento que es utilizado como vivienda por el hogar propietario del mismo, tanto las viviendas utilizadas para alojamiento habitual (las denominadas «viviendas principales») como las viviendas de vacaciones.

El problema subsiguiente es cómo valorar esa producción. El criterio recomendado en el SCN/ SEC es relativamente sencillo de exponer: la producción «se mide por el valor estimado del alquiler que pagaría un inquilino por el mismo alojamiento, toman-

10 También existe algún problema de tipo metodológico: por ejemplo, la valoración de las viviendas que se ceden gratuitamente o a precios reducidos. 
do en consideración elementos como la situación, el equipamiento de la zona, etc. así como el tamaño y la calidad de la vivienda en cuestión». (SEC95, Para. 3.64).

Criterio fácil de formular, pero difícil de concretar en la práctica. Para buscar ese valor se utilizan distintos procedimientos, siendo hoy en día el preponderante (obligatorio incluso en la Unión Europea) el método de la estratificación ${ }^{11}$. Consiste, como indica el término, en distribuir el parque total de viviendas en diversos estratos por tipología de las viviendas, tipología que se asocia con un determinado precio de alquiler de las viviendas en cada estrato.

La estratificación del parque de viviendas se realiza con una serie de parámetros obtenidos de los censos de viviendas (clase de vivienda, superficie, régimen de tenencia, instalaciones, número de habitaciones, etc.) y edificios (ubicación del edificio, tipo de edificio, año de construcción, instalaciones y servicios, etc.). Pero es necesario contar con datos de alquileres reales representativos de cada estrato de viviendas. Porque finalmente, se trata de dar un valor monetario a cada categoría o estrato de viviendas.

Estos son criterios generales para todos los tipos de viviendas. En principio, parece posible aplicar para las viviendas de vacaciones estos mismos convenios, pero introduciendo como es obvio un criterio de tiempo de utilización, ya que no sería lógico asignarles el mismo valor que a una vivienda de uso habitual.

\subsection{Problemas específicos en los flujos internacionales e interregionales.}

Un caso singular a considerar, es el de las viviendas propiedad de no residentes. En el SCN/SEC, existe un convenio adicional al respecto: El mero hecho de poseer terrenos o edificios en el territorio económico se considera suficiente para que el propietario se considere «residente» en el país. Para poder respetar los equilibrios contables se crea una unidad ficticia tratada como si fuera controlada por la unidad propietaria noresidente. Por tanto, los alquileres y rentas pagados por tenedores de tierra o edificios se supone que se pagan a la unidad residente ficticia que a su vez, hace una transferencia de una renta de la propiedad al verdadero propietario no-residente. Es decir, que el

11 El criterio tradicional es el de la «auto-valoración» en las encuestas (a hogares): los propietarios de viviendas reflejan en los cuestionarios lo que ellos estiman como valor a pagar por una vivienda equivalente. El grado de subjetivismo implícito en este método es evidente, y, por lo general, conduce a una sobre-valoración de los alquileres imputados. 
correspondiente excedente de explotación neto se registra como renta primaria pagada al resto del mundo.

Con esta renta, el no residente «adquiere» (ficticiamente) los servicios generados por el uso de su propia vivienda en otro país o región. Por tanto, el valor del alquiler de las viviendas pertenecientes a no residentes se registra como exportación de servicios.

Una conclusión de estos criterios y convenios de la contabilidad nacional, de cara a la elaboración de la CST es que, en definitiva, los alquileres imputados a viviendas ocupadas por sus propietarios en un territorio concreto hacen abstracción de si el propietario es o no un no-residente, ya que todos esos alquileres entrarán a formar parte del «PIB vinculado al turismo» de esa zona concreta. Por tanto, el total se podría estimar de manera conjunta.

Distinto es el tema de la estimación de los flujos de bienes y servicios con el resto de los países y del cálculo de la renta nacional y regional, que evidentemente se ven notablemente afectados por la eventual existencia de un número relevante de viviendas en poder de no-residentes.

\subsection{Necesidades estadísticas y viviendas turísticas}

Decíamos antes que la esencia de los problemas es de índole conceptual, ya que proviene de esos convenios tan singulares de las cuentas nacionales. Esto es así, pero también es obvio que criterios tan singulares requieren de criterios prácticos de estimación que permitan pasar de esas sugerencias conceptuales a mediciones numéricas; $\mathrm{y}$, en último término, el problema lleva a la necesidad de fuentes de información no menos específicas.

Adicionalmente en las viviendas turísticas, a los ya notables requerimientos que plantean los criterios contables para las viviendas en general, se une la necesidad de contar con información sobre nivel o tasa de uso (un tiempo medio de utilización) de las mismas.

Evidentemente, al hablar de viviendas turísticas nos encontramos con el problema general de que, desde un punto de vista estadístico no hay una solución única ni definitiva sino diferentes aproximaciones al fenómeno.

Esto sucede por un lado en la perspectiva de oferta: Solo en fuentes de información de tipo censal o que provengan de registros administrativos, sería posible acercarse al universo de la oferta. Pero siempre se tratará de una oferta potencial, porque lo que se puede captar son viviendas secundarias de las familias. Es muy problemático determinar cuántas de estas y en qué medida se utilizan como alojamiento («turístico» o de otro 
tipo) por sus propietarios o son viviendas que se mantienen como bienes de inversión «puros».

Tampoco en una encuesta de demanda, ni aún cuando fuera exhaustiva, sería posible garantizar un $100 \%$ de la información necesaria, por la incidencia de por ejemplo el tema las viviendas propiedad de no residentes o la utilización de viviendas «principales» en ocasionales viajes turísticos.

Por tanto, el tipo de soluciones que se deben plantear a estos importantes retos estadísticos pasan en primer lugar, por la combinación y contraste de investigaciones por demanda y oferta, además de otras medidas estadísticas (Libreros y cañada (2010)): la necesidad de la puesta en marcha de módulos específicos en las encuestas a hogares y en los censos; el aprovechamiento y la explotación, como base para contrastes o universos de fuentes administrativas (catastro, fuentes tributarias) y de otras fuentes «indirectas» para medir el universo y la tasa de uso turística ${ }^{12}$.

En segundo lugar, de nuevo aquí se vuelve a resaltar la necesidad de recurrir a esquemas de tipo matricial o de contraste origen/ destino, que traten de solventar la posible falta de simetría que en la actualidad puede existir entre las estimaciones independientes de las diferentes zonas. Con un ejemplo sencillo: en la actualidad las estimaciones que realizan dos países o dos regiones que pueden estar vinculadas por este fenómeno (pensemos que un área es «exportadora» de estos servicios y la otra «importadora») se llevan a cabo de forma independiente, sin que sea posible saber el grado de compatibilidad entre las mismas. Eso puede afectar de manera significativa a los datos de las balanzas de pagos y cuentas nacionales/ regionales.

La necesidad de elaborar estas matrices (o esquemas similares) interregionales o internacionales conlleva la necesidad de una identificación de los flujos no monetarios aproximados o potenciales: en oferta, la distribución territorial «cruzada» de viviendas «secundarias»; en demanda, datos de uso turístico de este tipo de viviendas. Es decir, desde la perspectiva específica de las mencionadas matrices regionales de consumo turístico, de nuevo se plantea la necesidad de realizar una estimación de las matrices desagregada para determinadas categorías de productos y/ segmentos de demanda, en este caso del alquiler imputado las viviendas en propiedad. Este tipo de matrices debería ser específica para este producto, porque su dimensión y características son diferentes de las de otros segmentos de oferta/ demanda turísticas.

12 Por ejemplo, la utilización de los datos de compañías de servicios públicos (luz, agua,) como indicativo del uso efectivo de las viviendas. 
En definitiva, aunque el origen de este nuevo interés por el tema de los alquileres imputados haya surgido en el ámbito internacional, todo el análisis es directamente aplicable a, y ha promovido el correspondiente resurgimiento del tema en, el ámbito regional.

\section{REFLEXIÓN FINAL}

En este trabajo se presentan algunas de las novedades metodológicas e iniciativas que están llevando a cabo las instituciones internacionales para ampliar el alcance de la CST, fundamentalmente al ámbito regional.

Así en primer lugar, se resumen algunas de las iniciativas promovidas por la OMT en el marco de la Red INROUTE, haciendo especial énfasis en la necesidad de elaborar matrices interregionales de consumo turístico. A través de estas matrices es factible mejorar un sistema integrado de estimaciones regionales sobre el impacto del turismo. Por otra parte, se subraya la posibilidad de explorar algunas alternativas para obtener estimaciones de la demanda a partir de datos de oferta (agencias de viajes, alojamiento, transporte...).

En segundo lugar, se describen las propuestas destinadas a solventar las limitaciones de los criterios actuales de la CST sobre definición de variables macro (y modelos de impacto del turismo) a escala nacional y regional. En el documento se presentan las dos principales alternativas, basadas en la demanda final turística, y en la denominada «demanda final ampliada».

Finalmente, se analiza el tratamiento de los alquileres imputados a las viviendas turísticas en una CST. A pesar de la importancia del fenómeno (tanto a escala interna de los países como en el marco internacional) puede decirse que es uno de los aspectos todavía hoy pendientes de ser abordados de forma consistente en la CST. En el trabajo se apuntan recomendaciones de tipo metodológico y también de carácter estadístico, dadas las considerables carencias de información actuales. También se sugiere, en lo referente a los flujos inter-territoriales (entre regiones y entre países) vinculados a este producto, la necesidad de elaborar sistemas de estimación cruzada de los flujos entre las zonas implicadas. 


\section{REFERENCIAS BIBLIOGRÁFICAS}

Bonn, M. (2008): «A comparison of three economic impact models for applied hospitality and tourism research». Tourism Economics, 2008, 14 (4), 769-789

CAÑAdA, A. (2004): «Instrumentos de medida del turismo: la Cuenta Satélite del Turismo». Papeles de Economía Española, no 102, pp. 2-28.

- (2009): «Regional-TSA: potential and problems in developing sub-national TSA». Ponencia presentada en la conferencia «Tourism Satellite Accounts: Inputs, Processes, and Actors». ONS, Londres, 21-22 Mayo, 2009.

- (2010-a): «Efectos de capitalización del I+D en las cuentas nacionales: aproximación a una cuenta satélite de I+D». Revista de economía, no 853, pp. 89-108.

- (2010-b): «Nueva introducción práctica a la contabilidad nacional. Adaptada al SEC2010». (Próxima publicación).

CAÑAda, A. y RoIG, R. (2002): «La contabilidad nacional según el SEC95 como marco para la estimación de la cuenta satélite del turismo de España». Estudios Turísticos, n ${ }^{\circ}$ 151, pp. 5-37 Eurostat (2009): «TSA in the European Union». Eurostat, 2009.

Holtz-Eakin, D (2001): «Capital in a Tourism Satellite Account». Tourism Economics, 7, pp. 223-232.

INE (2009): «Cuenta Satélite del Turismo de España: serie contable 1995-2008», 2009.

Libreros, M. y CAÑAdA, A. (2010): «Vacation home ownership in a globalized world». Documento de trabajo, OMT.

Organización Mundial del Turismo (2008): «Tourism Satellite Account: Recommended Methodological Framework».

Stevens, B. AND Rose, A. (1985): «Regional input-output methods for tourism impact analysis». En: Propst, D. B. (Compiler). «Assessing the Economic Impacts of Recreation and Tourism» (pp. 16-22). Asheville, N.C. 


\title{
AneXo 1. CONCEPTOS BÁsICOS DE CONSUMO TURÍstico EN UNA CST
}

\author{
El esquema A.1 resume los conceptos principales del «consumo turístico» ${ }^{13}$ en una \\ CST.
}

Esquema A.1.-Clasificación del consumo turístico en la CST

\begin{tabular}{|c|c|c|c|c|}
\hline & \multicolumn{2}{|c|}{$\begin{array}{l}\text { Tipo de productor que ofrece el producto } \\
\text { (1) }\end{array}$} & \multirow[b]{2}{*}{ TOTAL } \\
\hline & & $\begin{array}{l}\text { Productores } \\
\text { residentes (1) }\end{array}$ & $\begin{array}{l}\text { Productores no } \\
\text { residentes (1) }\end{array}$ & \\
\hline \multirow{3}{*}{ 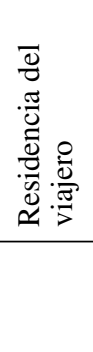 } & Residentes & $\begin{array}{l}\text { Consumo } \\
\text { turístico interno }\end{array}$ & $\begin{array}{l}\text { Consumo turístico } \\
\text { emisor }\end{array}$ & $\begin{array}{l}\text { CONSUMO } \\
\text { TURÍSTICO } \\
\text { NACIONAL }\end{array}$ \\
\hline & No residentes & $\begin{array}{l}\text { Consumo } \\
\text { turístico } \\
\text { receptor }\end{array}$ & & \\
\hline & TOTAL & $\begin{array}{c}\text { CONSUMO } \\
\text { TURÍSTICO } \\
\text { INTERIOR }\end{array}$ & & \\
\hline
\end{tabular}

(1) Criterio aproximado: véase el texto.

El «consumo turístico interno» recoge los gastos ligados al turismo interno, es decir, los viajes de los residentes dentro del propio territorio en el que «residen» y los gastos vinculados a viajes a otras zonas, pero que se materializan en una compra de servicios en el territorio de residencia.

$\mathrm{El}$ «consumo turístico receptor» incluye: el «consumo de no residentes en el territorio económico» ${ }^{14}$; otras exportaciones de servicios, que reflejan los servicios prestados por unidades residentes a los visitantes no residentes (por ejemplo, cuando un turista no residente llega a un territorio utilizando una compañía de transporte residente).

De manera análoga, para el consumo turístico emisor, las importaciones incluyen el «consumo de los residentes en el resto del mundo» pero también otras importaciones relacionadas con los viajes turísticos (básicamente el transporte).

${ }^{13}$ En el texto por simplicidad se utilizan indistintamente los términos gasto o consumo, que en las cuentas nacionales presentan diferencias conceptuales. Véase Cañada (2010-b)

14 Esta rúbrica se incluiría en la CST a excepción de determinadas partidas: rentas de trabajadores temporeros y fronterizos. 
Si se suman los dos componentes que aparecen en la fila relacionada con los viajes de los residentes, se tiene el consumo turístico nacional; y si se suma la columna del gasto atribuible a los productores residentes, se tiene el consumo turístico interior.

La relación entre los conceptos de consumo turístico y las variables de cuentas nacionales se ilustra gráficamente en el esquema A.2. En el esquema aparecen solo los componentes del «consumo turístico» y los conceptos de cuentas nacionales que lo definen: gasto en consumo final de hogares; consumo de no residentes — que aparece aquí desagregado en un vector de productos- ; gasto en consumo final de AAPP/ ISFLSH; y exportaciones.

En el consumo interno, al introducir la diferenciación cuando el viaje responde a un motivo de trabajo (en la terminología de la CST «viajes de negocios») se incluyen consumos intermedios de las empresas residentes por desplazamientos de su personal en esos «viajes de negocios» (básicamente los gastos de transporte, alojamiento). Pero los gastos en manutención tienen la consideración de «remuneración en especie» y por tanto se traducen en «gasto en consumo final de los hogares». 
Esquema A.2.- - Las variables de demanda turística en una CST y su relación con la contabilidad nacional a partir de la Tabla de Destino ${ }^{15}$.

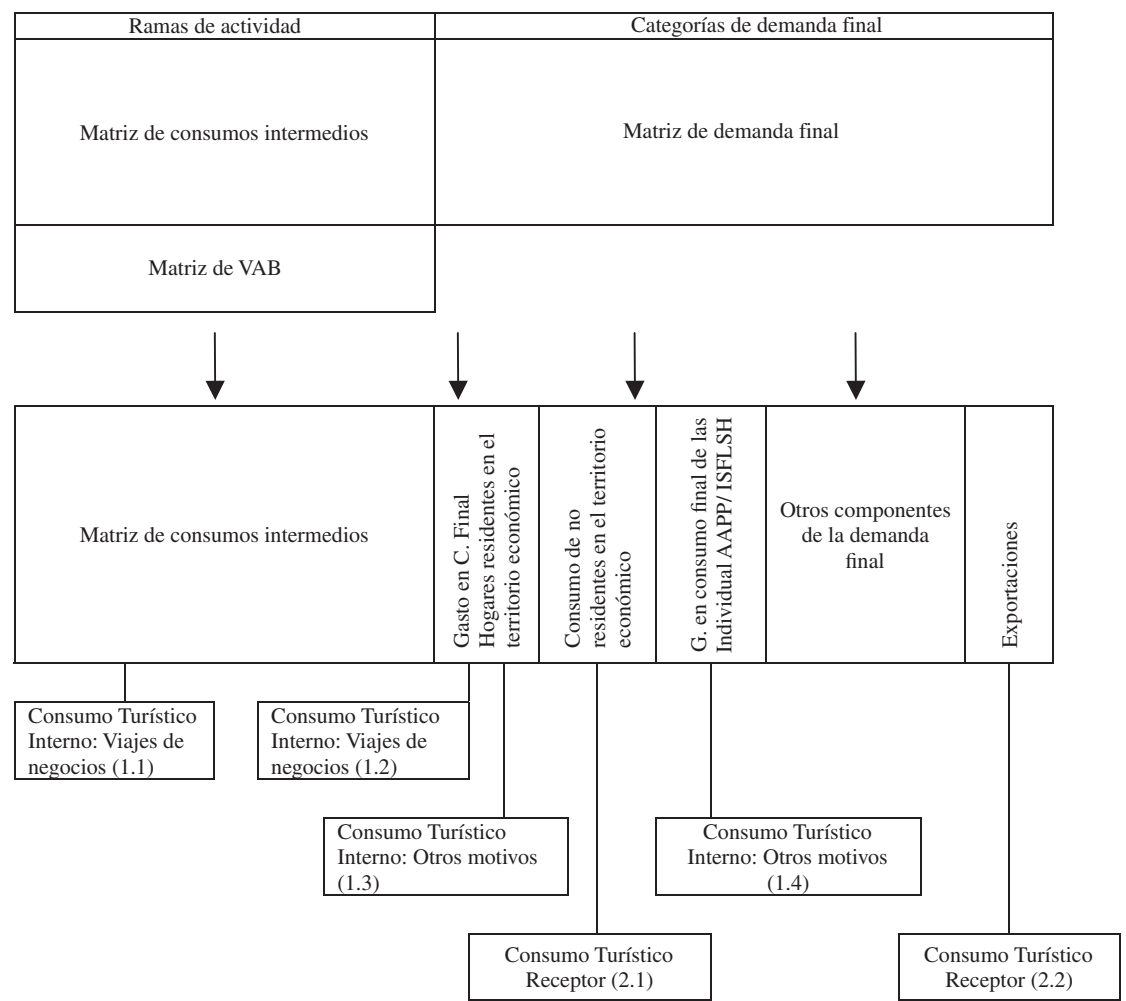

15 El consumo de no residentes aparece aquí desagregado en un vector de productos. En las TOD está implícito en el vector de gasto en consumo de los hogares por productos y aparece de forma agregada, junto con el "consumo de residentes en el resto del mundo", como partida de ajuste que permite reflejar unos totales de gasto en consumo «nacional». (Cañada (2010-b)). 


\section{ANexo 2. UNA FORMULACión SIMPLE DEL PIB EN LA CST Y UN MODELO I-O APLICADO AL TURISMO \\ 1. Obtención del PIB turístico en la CST}

Sea $\mathrm{D}$ la demanda total de la economía y Z el valor de la producción. Utilizando las TOD, la primera se define por productos (“i”), y la segunda por ramas (“j”) como:

$$
\mathrm{D}=\Sigma \mathrm{Di} \quad \mathrm{Z}=\Sigma \mathrm{Zj}
$$

i $\quad \mathrm{j}$

Cada una de las ramas de actividad tiene diversificación productiva de forma que

$$
\mathrm{Zj}=\Sigma \mathrm{Zij}
$$

Siendo $\mathrm{Zij}$ cada uno de los elementos de la matriz de producción en la tabla de origen. Si se indica con la letra $\mathrm{T}$ la parte de cada variable vinculada con el turismo, la demanda turística total, DT, sería la suma de las demandas turísticas de los i productos

$$
\mathrm{DT}=\Sigma \mathrm{DTi}
$$

Si una DTi es abastecida por diferentes ramas, cada una de las cuales produce para el turismo ZTij, entonces

$$
\mathrm{DTi}=\underset{\mathrm{j}}{\sum \text { ZTij }}
$$

Y la parte orientada al turismo en la producción de cada rama sería:

$$
\mathrm{ZTj}=\Sigma \mathrm{ZTij}
$$

Para llegar al valor añadido $\mathrm{Vj}$, si $\mathrm{Xj}$ es el total de los consumos intermedios

$$
\mathrm{Vj}=\mathrm{Zj}-\mathrm{Xj}
$$

Y la correspondiente al valor añadido generado por el turismo

$$
\mathrm{VTj}=\mathrm{ZTj}-\mathrm{XTj}
$$


La suma de estos valores añadidos, más los Impuestos netos de subvenciones $(\tau)$ vinculados a la demanda turística (definida por productos) permite obtener el PIB turístico:

$$
\operatorname{PIBT}=\underset{j}{\sum} \mathrm{VTj}+\underset{\mathrm{i}}{\sum} \boldsymbol{i} \mathrm{i}
$$

\section{Un modelo I-O simplificado para evaluar el impacto de la demanda turística}

\subsection{Procedimiento de demanda final turística.}

En términos del PIB turístico, el procedimiento de demanda final es tan simple como diferenciar en la demanda por el turismo:

$$
\mathrm{DT}=\mathrm{XT}+\mathrm{YT}
$$

Siendo XT la demanda turística intermedia e YT la demanda turística final. Y el PIB sería:

$$
\mathrm{PIBT}=\mathrm{YT}=\Sigma \mathrm{YTi}
$$

(Se supone que YT está valorada adecuadamente — a precios de adquisición).

Pero esta alternativa nos permite ya movernos en el campo de los modelos de impacto del turismo, y se podrían aplicar directamente esquemas tipo "Leontief"16. Por

${ }^{16}$ El modelo que se utiliza es una aproximación al modelo de Leontief, puesto que en las TOD las funciones de producción implícitas son funciones compuestas donde cada rama puede elaborar varios productos. Por tanto, hay que utilizar aproximaciones basadas en las hipótesis de tecnología y en los coeficientes que se obtienen de la matriz de producción de la tabla de origen (Cañada (2010-b)). Aquí se ha utilizado la que se considera conceptualmente más sólida, que es la basada en la hipótesis de tecnología del producto. 
ejemplo, partiendo de un modelo I-O "aproximado" utilizando las TOD, el valor de la producción asociada a un determinado vector de demanda final sería ${ }^{17}$ :

$$
\mathrm{Z}=\mathrm{U}^{-1}\left(\mathrm{I}-\mathrm{W} \mathrm{U}^{-1}\right)^{-1}(\mathrm{Y}-\mathrm{M}) \text {. }
$$

Donde las variables son ahora matrices o vectores obtenidos de las TOD para "n" productos y "m" ramas. Z, Y, M son vectores (n x 1): Z es el vector de producción por productos o ramas homogéneas; $\mathrm{Y}$, el vector de demanda final por productos; $\mathrm{M}$ el vector de importaciones por productos. I, W, U son matrices ( $\mathrm{n} \times \mathrm{m}$ ): I es la matriz identidad; W es la matriz de los coeficientes técnicos Wij obtenida de la tabla de destino; U, la matriz de los coeficientes de especialización Uij obtenidos en la tabla de origen.

Obsérvese que esta ecuación no sería aplicable directamente a la obtención del impacto producido por la demanda turística DT en una zona, puesto que los gastos de los viajes de negocios estarían simultáneamente como variable endógena, (incluidos en las matrices que definen los multiplicadores) y como variable exógena. Sí es factible en cambio aplicar la ecuación para obtener la producción directa e indirecta ligada a la demanda final turística:

$$
\mathrm{ZT}=\mathrm{U}^{-1}\left(\mathrm{I}-\mathrm{W} \mathrm{U}^{-1}\right)^{-1}(\mathrm{YT}-\mathrm{M}) .
$$

Donde ZT (producción multiplicativa del turismo) es un vector de la producción turística de todas las ramas de la economía que es generada directa e indirectamente (a través de las interconexiones productivas) por la demanda final YT.

\subsection{Procedimiento de demanda final turística "ampliada"}

En el segundo procedimiento propuesto, de "exogeneización" de los consumos intermedios, sería necesario en primer lugar redefinir la demanda intermedia y la final, excluyendo de la primera los viajes por motivo de trabajo e incluyéndolos en la segunda. Así, el modelo equivalente a la ecuación [A5] de una TDO adaptada es:

$$
\mathrm{Z}=\mathrm{U}+^{*-1}\left(\mathrm{I}-\mathrm{W}^{*} \mathrm{U}^{*-1}\right)^{-1}\left(\mathrm{Y}^{*}-\mathrm{M}\right) \text {. }
$$

17 Tomando para simplificar el modelo de coeficientes "totales". La alternativa seria utilizar los flujos "interiores". 
Donde $\mathrm{U}^{*}, \mathrm{~W}^{*}$ e $\mathrm{Y}^{*}$, son versiones modificadas de las matrices o vectores de la ecuación [A6]. En términos de la demanda final turística quedaría:

$$
\mathrm{ZT}=\mathrm{U}^{*-1}\left(\mathrm{I}-\mathrm{W}^{*} \mathrm{U}^{*-1}\right)^{-1}\left(\mathrm{YT} \mathrm{T}^{*}-\mathrm{M}\right)=\mathrm{U}^{*-1}\left(\mathrm{I}-\mathrm{W}^{*} \mathrm{U}^{*-1}\right)^{-1}(\mathrm{DT}-\mathrm{M})
$$

Ya que $\mathrm{YT}^{*}$ coincide ahora con la demanda turística total DT, tal y como se define en una cuenta satélite.

Como se menciona en el texto (epígrafe 3) la magnitud global de este ajuste se reduce a la parte de mercado, ya que por los criterios de la metodología contable (SCN/ SEC) la reclasificación de los gastos de viaje de las ramas de no mercado desde consumo intermedio a demanda final, tiene un efecto nulo en términos agregados del PIB.

En efecto, en el sistema de cuentas nacionales cualquier gasto corriente de las ramas de no mercado forma parte del valor de la producción (ya que ésta se mide por los costes); y posteriormente, esta producción de no mercado se traduce en el correspondiente gasto final en consumo. (Cañada (2010-a)). El procedimiento propuesto en la CST se traduce en este caso en reasignar los gastos de viaje de empleados de las unidades de no mercado, de demanda intermedia al Gasto en consumo final de las AP. En lo referente al PIB de la economía se vería inalterado, porque la disminución del output y el GCF en servicios de no mercado se verían compensados por un mayor GCF en los productos que constituyen los gastos en viajes de negocios (transporte, alojamiento...).

El segundo aspecto positivo mencionado en el texto es que, al quedar toda la demanda turística como exógena, incluidos los gastos en viajes de negocios, se facilitaría el cálculo de la "aportación del turismo al PIB" (y de los multiplicadores de efectos directos e indirectos) para productos específicos del turismo ${ }^{18}$. Además se podría diferenciar el efecto de variaciones en este tipo de gasto, tanto de las actividades de mercado, como de la parte dependiente del sector público. En efecto, el vector YT* se podría diferenciar en:

$$
\mathrm{YT}^{*}=(\mathrm{CTH}+\mathrm{CTR}+\mathrm{CTAP})+\left(\mathrm{CT}^{\mathrm{S}}+\mathrm{CT}^{\mathrm{AP}}\right)
$$

Donde los cinco términos de la parte derecha son vectores definidos por productos: CTH es el (gasto en) consumo turístico (final) de los hogares; CTAP, el (gasto en) con-

18 Naturalmente, y para dar un visión equilibrada, los multiplicadores de tipo I-O que se manejan en esta versión ampliada son menores que en el modelo normal (al ser menor la matriz de consumos intermedios). 
sumo turístico (final) de AAPP (e ISFLSH); CTR, el consumo turístico receptor; $\mathrm{CT}^{\mathrm{S}}$ los gastos en viajes de negocios de las unidades de mercado; $\mathrm{CT}^{\mathrm{AP}}$ los gastos en viajes de negocios de las unidades de no mercado (para simplificar centrados en las AAPP). Es decir, los tres primeros términos eran los originales de la demanda final turística anexo 1-. Los dos últimos son los que se añaden en esta "versión ampliada"

Es decir, que este tema tiene un alcance mayor aún que el del análisis del turismo: como se ha señalado en la literatura (un resumen puede verse en Cañada (2010-b)) los sistemas I-O acordes con las metodologías contables (SCN, SEC) resultan limitados para determinados tipos de análisis (por ejemplo, no es posible examinar los efectos multiplicadores de la variación en partidas concretas de gastos corrientes del sector público). En cambio, en esta propuesta sí puede estudiarse por ejemplo, el efecto económico de una variación en los gastos de viajes de los empleados de las AAPP (por ejemplo, en momentos de recesión económica). 